\title{
Characterization of a GM7 glioblastoma cell line showing CD133 positivity and both cytoplasmic and nuclear localization of nestin
}

\author{
TOMAS LOJA ${ }^{1,2}$, PETR CHLAPEK ${ }^{1}$, PETR KUGLIK ${ }^{1,3}$, MARTINA PESAKOVA ${ }^{1}$, \\ ALEXANDRA OLTOVA $^{3}$, PAVEL CEJPEK ${ }^{4}$ and RENATA VESELSKA ${ }^{1}$ \\ ${ }^{1}$ Laboratory of Tumor Biology and Genetics, Institute of Experimental Biology, School of Science, \\ Masaryk University, Kotlarska 2, 61137 Brno, ${ }^{2}$ Department of Biology, School of Medicine, \\ Masaryk University, Komenskeho nam. 2, 66243 Brno, ${ }^{3}$ Department of Medical Genetics, \\ University Hospital Brno, Cernopolni 9, 61300 Brno, ${ }^{4}$ Department of Neurosurgery, \\ School of Medicine, Masaryk University, Komenskeho nam. 2, 66243 Brno, Czech Republic
}

Received April 18, 2008; Accepted August 27, 2008

DOI: $10.3892 /$ or_00000198

\begin{abstract}
A newly established GM7 cell line was derived from the tumor tissue of a 65-year-old man surgically treated for a relapse of glioblastoma multiforme that occurred 10 months after first surgery following radiotherapy. GM7 cells exhibit spindle or glia-like morphology, and multinucleated giant cells are also present in the culture. The cells proliferate rapidly (PDT is about $18 \mathrm{~h}$ ) and tend to grow in multilayer without contact inhibition. Using G-banding and SKY, the GM7 cell line was identified as near-triploid with a large number of structural and numerical abnormalities. Repeated karyotyping during long-term cultivation confirmed a chromosome number of $70 \pm 3$ chromosomes per cell. Special attention was paid to the immunocytochemical analysis of protein markers in this cell line; GM7 cells showed strong positivity for CD133, vimentin, nestin, NF-160 and S-100 protein and weak positivity for GFAP and NSE, but were negative for synaptophysin. The most important features of the GM7 cell line are its stable phenotype

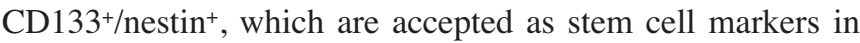
neural stem/progenitor cells, and especially unusual intracellular localization of the IF protein nestin, which was detected and repeatedly confirmed both in the cytoplasm and cell nucleus. For this reason, the new GM7 glioblastoma cell line represents an important model suitable not only for further studies on glioblastoma biology and cancer stem cells, but
\end{abstract}

Correspondence to: Dr Renata Veselska, Laboratory of Tumor Biology and Genetics, Institute of Experimental Biology, School of Science, Masaryk University, Kotlarska 2, 61137 Brno, Czech Republic

E-mail: veselska@sci.muni.cz

Key words: glioblastoma cell line, nestin, intermediate filaments, CD133, cancer stem cell markers particularly for the detailed investigation of the role of nestin in transformed cells.

\section{Introduction}

Glioblastoma multiforme (GBM, WHO grade IV) is the most malignant primary intracranial tumor affecting predominantly adults. The frequency of this tumor is 5-7 cases per 100,000 people with a higher incidence in men than in women (1). Despite recent advances in neurosurgery, radiotherapy and chemotherapy, the prognosis for patients with GBM is still poor, with a median post-treatment survival of about one year $(2,3)$.

GBM belongs to the high-grade astrocytomas. A typical feature of this group is a high degree of intratumoral heterogeneity in histomorphology and genetic alterations. Tumorigenesis of GBM represents a complex process involving accumulation of genetic lesions that provide a growth advantage to the transformed glial cells. Amplification of the EGFR gene in the $7 \mathrm{p} 12$ region and mutation or deletion of the TP53 gene in the 17p13.1 region appear to be the most important of these changes $(1,4-7)$. Furthermore, polysomy of chromosome 7 as well as partial or complete loss of chromosome 10 have been described as genetic markers of GBM $(1,6-8)$.

In addition to the classical histopathomorphogical classification of CNS neoplasias, the evaluation of intermediate filament (IF) protein expression using immunocytochemistry may be also employed in the precise diagnostics of high-grade astrocytomas. This approach includes detection of glial fibrillary acidic protein (GFAP), vimentin, nestin, neurofilament (NF) proteins and cytokeratins; moreover, S-100 protein, neuron-specific enolase (NSE), synaptophysin and epithelial membrane antigen (EMA) are also frequently assessed (9-11).

Established cell lines derived from this type of tumor represent an important tool for the detailed study of several aspects of glioblastoma pathology on cellular and molecular 
levels, which may aid in resolving diagnostic as well as therapeutic issues. Many reports on the establishment and characterization of different glioma cell lines have been published, including reports on cell lines derived from glioblastomas $(10,12-15)$.

Some of these cell lines are widely employed for investigations of brain tumor biology - U87MG, A172, U373MG and U251MG lines should be listed as the most frequently used of these cell lines (16-20). A typical feature of the glioblastoma cell lines is, similar to glioblastomas in vivo, heterogeneity in karyotype and intermediate filament (IF) protein profiles as well as other intracellular protein markers. Therefore, a precise description of each newly established cell line is a prerequisite for its use in glioblastoma research.

During recent years, special attention has been paid to the detailed investigation of IF protein nestin co-expression together with CD133 cell surface antigen in tumor cells because this phenotype is considered to be a marker of cancer stem cells (CSCs) (21-24). This fact was experimentally proved, for example, in glioblastoma multiforme (25) and malignant melanoma (26).

In this study, we characterized a newly established GM7 cell line using cytogenetic and cytochemical approaches. This cell line was derived from the tumor tissue of a patient diagnosed with GBM. In our previous work, GM7 cell line was reported to be one of our derived cell lines showing nestin localization in cell nucleus (27). Due to the fact that none of the most frequently used glioblastoma cell lines as reported above shows this important morphological feature, our next research was focused on a detailed characterization of this cell line. In addition to results concerning cell morphology, karyotype analysis and expression of intermediate filament proteins and other neuroglial markers, the most important finding for the GM7 cell line was its CD133+/nestin ${ }^{+}$ phenotype and the stable unusual intracellular localization of the IF protein nestin, which was confirmed repeatedly both in the cytoplasm and cell nucleus.

\section{Materials and methods}

Cell culture. The GM7 cell line was derived from a biopsy sample of tumor tissue from a 65-year-old male. This tumor was histologically characterized according to the WHO classification as astrocytoma grade IV. Mechanical disaggregation of tumor tissue and primary culture were performed as previously described (27). After subcultivation, the GM7 cell line was maintained in DMEM (PAA Laboratories, Linz, Austria) supplemented with $20 \%$ fetal calf serum (PAA), $2 \mathrm{mM}$ glutamine and antibiotics: $100 \mathrm{IU} / \mathrm{ml}$ of penicillin and $100 \mu \mathrm{g} / \mathrm{ml}$ of streptomycin (Bio-Whittaker, Inc., Walkersville, MD, USA) under standard conditions $\left(37^{\circ} \mathrm{C}\right.$, atmosphere of $95 \%$ air:5\% $\mathrm{CO}_{2}$ ) and passaged 3 times per week. This cell line was also successfully cryopreserved at different passages.

Cell morphology. Cell morphology was assessed and documented by direct observation of living cells and Giemsa staining. Thereafter, cells growing on glass coverslips were rinsed in PBS and fixed in methanol:PBS mixture (1:1) for 2 min and in methanol only for $10 \mathrm{~min}$ at RT. The cells were subsequently dried, stained with an undiluted Giemsa stain for 2 min and with Giemsa diluted in water (1:4) for 2 min at RT. Finally, specimens were rinsed in water, dried and mounted onto glass-slides.

Population doubling time. Population doubling time (PDT) was determined using the MTT-assay. Briefly, a cell suspension at a concentration of $10^{4}$ cells $/ \mathrm{ml}$ was seeded into a 96-well microtitre plate in a volume of $200 \mu 1$ per well and the cells were allowed to grow under standard conditions. Measurement of cell proliferation was performed at 24, 48, 72 and $96 \mathrm{~h}$ intervals. For the MTT assay, the culture medium was removed and cells were washed with PBS and $220 \mu \mathrm{l}$ of DMEM containing MTT (Sigma Chemical Co., St. Louis, MO, USA), at a final concentration $455 \mu \mathrm{g}$ of MTT per ml of DMEM, was added to each well. After a 4-h incubation under standard conditions, the medium containing MTT was removed and replaced with $200 \mu 1$ of DMSO (Sigma) per well. Absorbance was measured at $570 \mathrm{~nm}$ using a Spectra Shell (SLT Laborinstrument GmbH, Salzburg, Austria) microplate reader and PDT was determined for the logarithmic growth phase. Experiments were repeated for different passages.

Flow cytometry. For DNA analysis, cells harvested in the logarithmic growth phase were incubated with $0.5 \mathrm{ml}$ of Vindelov's solution containing $10 \mathrm{mM}$ TRIS, $1 \mathrm{mM} \mathrm{NaCl}$, $10 \mu \mathrm{g} / \mathrm{ml}$ RNase, $50 \mu \mathrm{g} / \mathrm{ml}$ PI (all by Sigma) and $0.1 \%$ Triton X-100 (ICN Biomedicals, Inc., Eschwege, Germany) at RT for $30 \mathrm{~min}$. The fluorescence was measured using a FC500 Cytomics flow cytometer (Beckman Coulter, Inc.). A minimum of 15,000 events per sample was acquired and data were analyzed using WinMDI 2.8 software (Joseph Trotter, Scripps Research Institute, La Jolla, CA, USA); these data were not gated for analysis.

Karyotyping. For cytogenetic analysis, cells were treated with $5 \mu \mathrm{g} / \mathrm{ml}$ colchicine (Fluka, Buchs, Switzerland) for $4 \mathrm{~h}$. For G-banding, cells were rinsed in PBS, trypsinized and then washed 2 times in PBS using centrifugation. Consequently, the cells were treated with a $0.075 \mathrm{M} \mathrm{KCl}$ solution for 45 min at $37^{\circ} \mathrm{C}$. The cells were then fixed in a mixture of methanol and acetic acid (3:1), dropped onto glass slides and treated with $0.04 \%$ trypsin solution in Sörrensen buffer at $30^{\circ} \mathrm{C}$ for $30 \mathrm{sec}$. After washing with Sörrensen buffer, chromosomes were stained with Giemsa solution in water at RT for $3 \mathrm{~min}$. Specimens were observed in an Olympus BX-61 microscope; images were captured using a Vosskuhler 1300D CCD camera and G-banded mitoses were analyzed using BandView 3.0 software (Applied Spectral Imaging Ltd., Migdal Haemek, Israel). For SKY, the cells were processed according to our protocol as previously described (28).

Immunocytochemistry. For immunostaining of intracellular and cell surface antigens, cell suspensions at a concentration of $10^{4} \mathrm{cell} / \mathrm{ml}$ were seeded on glass coverslips and grown under standard conditions for $24 \mathrm{~h}$. Cells were then rinsed in PBS, fixed with 3\% paraformaldehyde (Sigma) in PBS for 20 min at RT and permeabilized with $0.2 \%$ Triton X-100 (INC Biomedicals) in PBS for $1 \mathrm{~min}$ at RT. For detection of the CD133 cell surface molecule this procedure was performed 

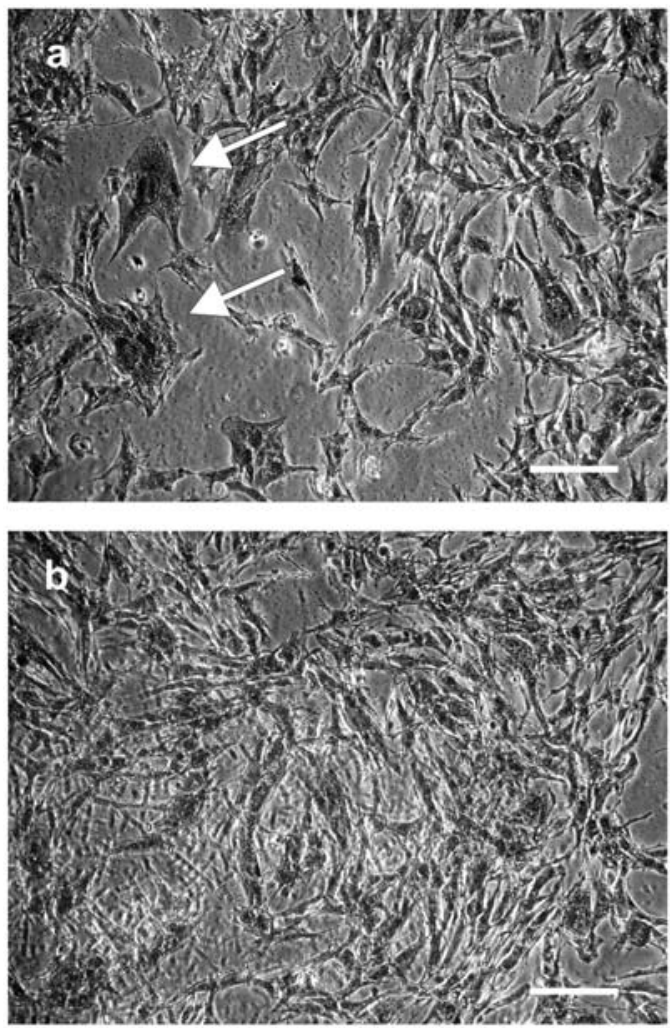

Figure 1. Morphology of GM7 cells. Two different cell types were found in the culture: the cells with spindle or glia-like morphology usually arranged in bundles (a), and multinucleated giant cells (arrows). Independently of cell density, GM7 cells tend to grow in multilayer without contact inhibition (b). Cells stained with Giemsa under phase-contrast microscopy are shown; bars, $100 \mu \mathrm{m}$.

without permeabilization. The cells were subsequently rinsed in PBS and incubated for 10 min with $2 \%$ BSA (PAA) to block non-specific binding of secondary antibodies. All intracellular antigens were visualized by indirect immunofluorescence. As primary antibodies, we used mouse monoclonal anti-glial fibrillary acidic protein (GFAP) antibody, clone G-A-5 (Sigma), mouse monoclonal antineurofilament 160 (NF160) antibody, clone NN18 (Sigma), mouse monoclonal anti-vimentin antibody, clone LN-6 (Sigma), mouse monoclonal human specific anti-nestin antibody (Chemicon International Inc., Temecula, CA, USA), mouse monoclonal anti-synaptophysin antibody, clone SVP-38 (Sigma), rabbit polyclonal anti-neuron specific enolase (NSE) antibody (Sigma), rabbit polyclonal anti-S-100 antibody (Sigma) and rabbit polyclonal anti-CD133 antibody (Abcam). The cells were treated with primary antibodies at $37^{\circ} \mathrm{C}$ for $1 \mathrm{~h}$ and then rinsed 3 times in PBS. Corresponding secondary antibodies were applied under the same conditions: anti-mouse antibodies conjugated with FITC or TRITC (Sigma) or antirabbit antibody conjugated with TRITC (Sigma). Finally, the cells were mounted onto glass slides in Vectashield mounting medium containing DAPI (Vector Laboratories, Burlingame, CA, USA). The cells were observed using an Olympus BX-61 fluorescence microscope. Micrographs were captured with a CCD camera COHU 4910 and analyzed using software Lucia 4.80-KARYO/FISH/CGH (Laboratory Imaging, Prague, Czech Republic). For detailed studies of intracellular antigens,

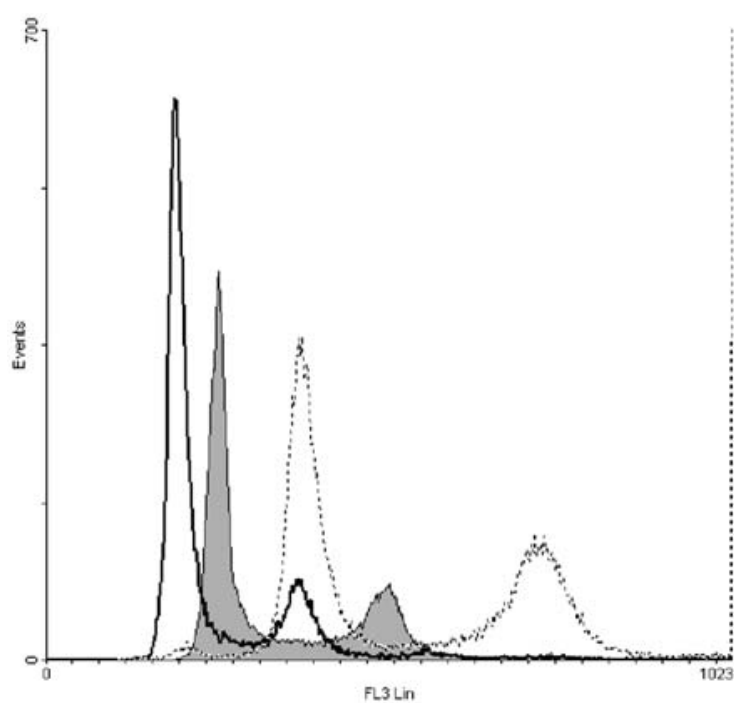

Figure 2. Representative flow cytometric analysis of DNA content in GM7 cell line. The GM7 cell line was identified as near-triploid $(\sim 3 n)$. Histogram shows results for analyzed GM7 cells (grey-black) overlaid with diploid (continuous line) and tetraploid (open peak) control cell lines.

a confocal imaging system FluoView-500 (Olympus) in combination with an inverted microscope Olympus IX-81 was used. Images were recorded using a CCD camera Olympus DP70 and analyzed with analySIS FIVE software (Soft Imaging System GmbH, Muenster, Germany) and FluoView Confocal Laser Scanning Microscope System 4.3 (Olympus).

Western blot analysis. For total protein analysis, the cells were resuspended in lysis buffer $(50 \mathrm{mM}$ Tris- $\mathrm{HCl} \mathrm{pH} 7.5$, $150 \mathrm{mM} \mathrm{NaCl}, 50 \mathrm{mM} \mathrm{NaF}, 1 \mathrm{mM}$ EDTA, $10 \%$ glycerol, $1 \%$ Triton $\mathrm{X}-100$ and protease inhibitors), incubated on ice for $10 \mathrm{~min}$ and then centrifuged at 15,000 rpm for $15 \mathrm{~min}$. Nuclear localization of nestin was also proven using Western blot analysis of both cytoplasmic and nuclear extracts. Briefly, cells were resuspended in hypotonic buffer $(10 \mathrm{mM}$ Tris- $\mathrm{HCl}$ $\mathrm{pH} 7.5,50 \mathrm{mM} \mathrm{NaCl}, 1 \mathrm{mM}$ EDTA and protease inhibitors) and allowed to swell for $10 \mathrm{~min}$ on ice. The cells were then lysed by addition of $10 \%$ Triton X-100 and vortexing. After centrifugation at $1,000 \mathrm{rpm}$ for $5 \mathrm{~min}$, the supernatant was used as the 'cytoplasmic' fraction. The nuclear pellet was resuspended in 'extraction' lysis buffer $(50 \mathrm{mM}$ Tris- $\mathrm{HCl} \mathrm{pH}$ 7.5, $300 \mathrm{mM} \mathrm{NaCl}, 50 \mathrm{mM} \mathrm{NaF}, 1 \mathrm{mM}$ EDTA, $10 \%$ glycerol, $1 \%$ Triton X-100 and protease inhibitors), incubated on ice for $10 \mathrm{~min}$ and centrifuged at $15,000 \mathrm{rpm}$ for $15 \mathrm{~min}$. The supernatant was then saved as the 'nuclear' fraction. Aliquots of protein extracts $(20 \mu \mathrm{g})$ were separated on $7 \%$ SDS-PAGE and electroblotted or directly dropped onto $0.45 \mu \mathrm{m}$ Hybond ECL nitrocellulose membrane (Amersham Biosciences, Little Chalfont, UK). The membrane was blocked with 3\% BSA at RT for $1 \mathrm{~h}$ and incubated with the same primary monoclonal antibodies as described above at $4^{\circ} \mathrm{C}$ overnight. The blots were developed using horseradish peroxidase-conjugated secondary antibodies (Sigma) at RT for $1 \mathrm{~h}$ and the ECL Plus detection system (Amersham) according to the manufacturer's protocol. At least three independent experiments were performed. 


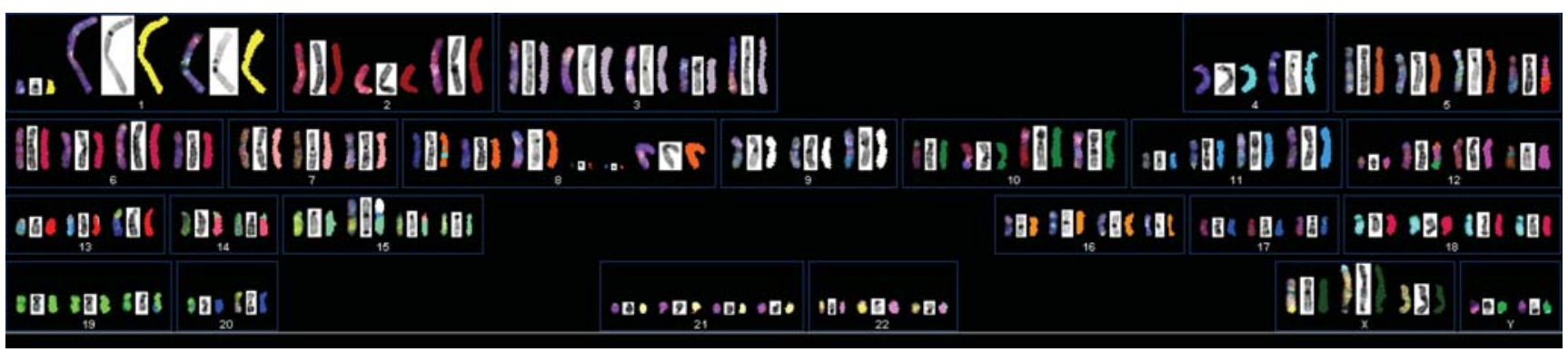

Figure 3. Representative SKY analysis of GM7 cell during short-term cultivation. The GM7 cell line was identified as near-triploid with large number of structural and numerical abnormalities. Karyotype of the metaphase showing RGB color of chromosomes (left), inverted DAPI-stained chromosomes (middle) and spectrally-classified pseudocolored chromosomes (right) are shown.
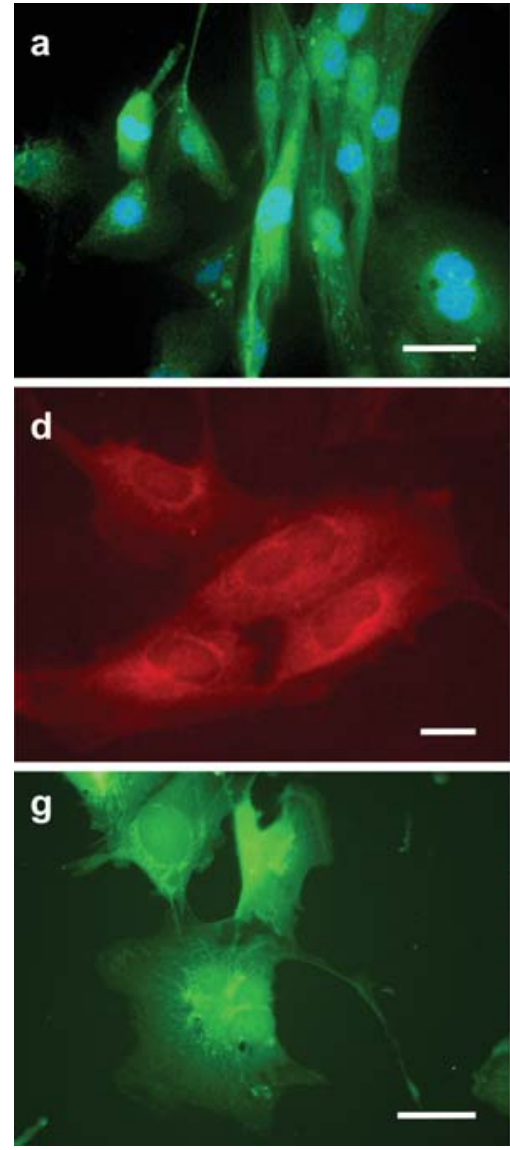
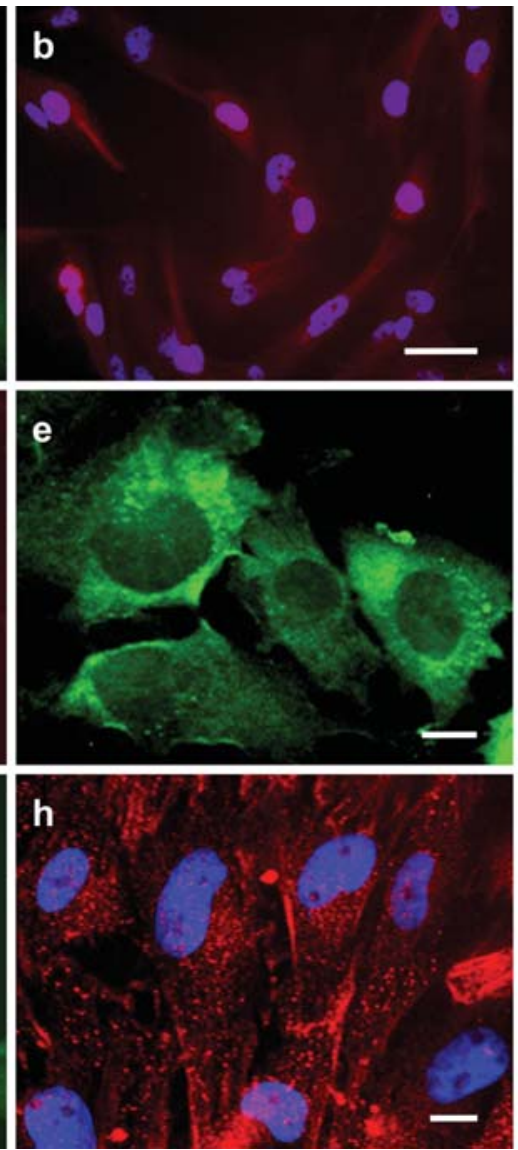
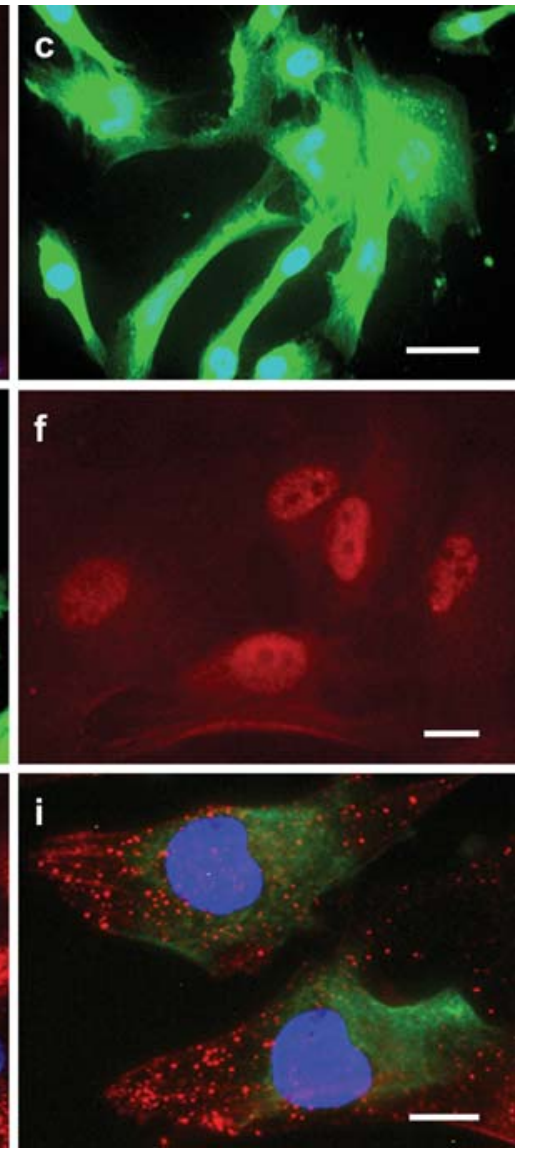

Figure 4. Expression of protein markers. A strong positivity for vimentin (a) and nestin (c), but only a poor reactivity for GFAP (b) in GM7 cell line was observed during the long-term cultivation. Intensive staining for S-100 protein (d) and NF160 (e) were also found in the cytoplasm of GM7 cells; strong signal for NSE was found in the cell nuclei but not in nucleoli (f). Nestin was observed in cell nuclei of GM7 cells using confocal microscopy (g). Cancer stem cell features of GM7 cell line were confirmed by detection of nestin expression (i) together with a strong expression of cell surface antigen CD133 (h). Vimentin (a, green), nestin (b, g and i, green) and NF160 (e, green) stained by indirect immunofluorescence using FITC-labeled secondary antibody; GFAP (b, red), S-100 protein (d, red), NSE (f, red), and CD133 (h and i, red) stained by the same method using TRITC-labeled secondary antibody; nuclei (a-c and $\mathrm{h}$-i, blue) labeled by DAPI are shown; bars, $50 \mu \mathrm{m}$ (a-c) and $25 \mu \mathrm{m}$ (d-i).

Transmission electron microscopy. For immunodetection of nestin in ultrathin sections, cells growing on coverslips were washed in PBS and consequently fixed with $2 \%$ paraformaldehyde (Sigma) in PBS for $1 \mathrm{~h}$ at RT. After rinsing in PBS and dehydration, cells were embedded into LR White (Polysciences Inc., London, UK). Labeling of ultrathin sections was performed on grids: nestin was detected using mouse monoclonal anti-nestin antibody (Chemicon) and anti-mouse gold particle conjugated secondary antibody
(Sigma). After the immunodetection was completed, the specimens were contrasted with $2.5 \%$ uranyl acetate (Lachema-Pliva, Brno, Czech Republic) for $20 \mathrm{~min}$ and with Reynolds' solution for $8 \mathrm{~min}$ at RT. The specimens were observed in a Morgagni 268 (D) transmission electron microscope (FEI Company, Hillsboro, OR, USA). Images were captured using a MegaView III CCD camera (Soft Imaging System) and analyzed by AnalySIS software (Soft Imaging System). 


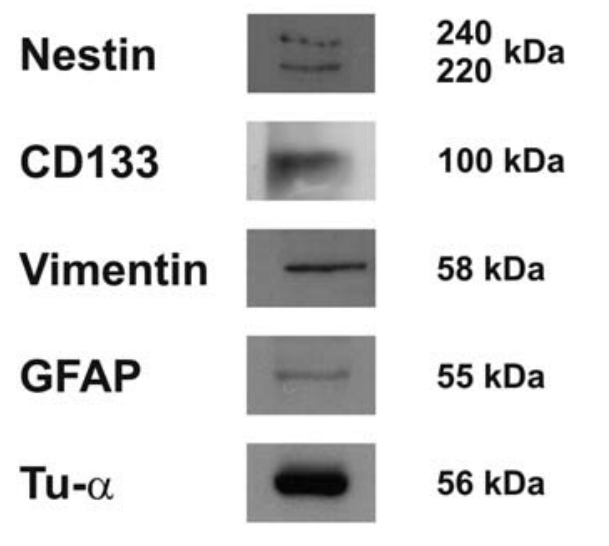

Figure 5. Western blot analysis of differences in intermediate filament protein expression. During long-term cultivation, Western blotting confirmed a reduced expression of GFAP and the strong positivity for vimentin and nestin in the GM7 cell line. Strong positivity for CD133 is also shown, tubulin serves as a control.

\section{Results}

The established GM7 cell line was characterized with respect to morphology, growth kinetics, karyotype analysis and expression of IF (GFAP, NF, nestin and vimentin) as well as other intracellular (S-100, NSE and synaptophysin) and cell surface (CD133) marker proteins. We have especially focused on the confirmation and the detailed analysis of the intracellular localization of nestin reported both in the cytoplasm and cell nucleus of GM7 cells in our previous study (27). To ensure the stability of the described features, the cells were analyzed repeatedly from 2 to 97 passages.

Cell morphology and growth parameters. The GM7 cell line was derived from the tumor tissue of a 65-year-old man surgically treated for relapse of glioblastoma multiforme. This relapse occurred 10 months after first surgery following radiotherapy. The sample of tumor tissue was taken from the geometrical hub of the tumor using stereotactic neurosurgery. After mechanical chopping of the tumor tissue, outgrowing cells were successfully subcultivated and the GM7 cell line was established. During the course of cultivation, this cell line was repeatedly cryopreserved. At present, cells are maintained under passage 97. The morphology of GM7 cells did not change during long-term cultivation. Two different cell types were found in the culture: most of the cells in the population exhibited spindle or glia-like morphology, but multinucleated giant cells were also present at a low frequency (Fig. 1a). Independently of cell density, GM7 cells are usually arranged in bundles (Fig. 1a) and tend to grow in multilayer without contact inhibition (Fig. 1b). Growth kinetic experiments determined the PDT to be approximately $18 \mathrm{~h}$. Analysis of the DNA content using flow cytometry confirmed the standard course of the cell cycle at different passages (Fig. 2).

Karyotype analysis. Analysis of DNA content also clearly showed the polyploidy of the GM7 cell line (Fig. 2). A detailed karyotype analysis was performed using G-banding and SKY techniques. During short-term cultivation (between passages 2 and 5), the GM7 cell line was identified as
Table I. Expression and intracellular localization of protein markers in the GM7 cell line during long-term cultivation. ${ }^{a}$

\begin{tabular}{lcccc}
\hline & \multicolumn{2}{c}{ Cytoplasm } & & Nucleus \\
\cline { 2 - 3 } \cline { 5 - 5 } Antigen & Passages $2-5$ & Passages $>6$ & \\
\hline GFAP & ++ & + & - \\
Nestin & ++ & +++ & $++/+++$ \\
Vimentin & +++ & +++ & - \\
NF-160 & $\mathrm{N}$ & +++ & - \\
NSE & $\mathrm{N}$ & + & +++ \\
S-100 & $\mathrm{N}$ & +++ & - \\
Synaptophysin & $\mathrm{N}$ & - & - \\
\hline
\end{tabular}

${ }^{a}$ Antigens were detected using indirect immunofluorescence: +++ , strong positivity; ++, medium positivity; +, low positivity; -, no positivity; $\mathrm{N}$ detection was not performed. CD133 cell surface antigen showed steadily strong positivity (+++) in GM7 cells.

near-triploid with a large number of structural and numerical abnormalities (Fig. 3): 78 82, XYY, $+\operatorname{der}(\mathrm{X}),+\operatorname{der}(\mathrm{X})$, $+\operatorname{der}(1),+\operatorname{der}(2),+3,+3,+\operatorname{der}(3), \operatorname{der}(4) \mathrm{t}(4 ; 4),+5,+5,+6,+6$, $+7,+8,+8,+\operatorname{der}(9),+\operatorname{der}(10),+11,+\operatorname{der}(11),+12,+\operatorname{der}(12)$, $+13,+15,+\operatorname{der}(15) \mathrm{t}(9 ; 15),+16,+16,+17,+18,+18,+19,+21$, $+21,+2$ dmin [cp5].

During long-term cultivation, the number of chromosomes became slightly reduced. Repeated karyotyping from passages 30 to 45 confirmed the diminished number of chromosomes to be $70 \pm 3$.

Expression of protein markers. Results obtained by immunocytochemical detection of intracellular marker proteins are summarized in Table I. Special attention was paid to the IF proteins GFAP, nestin and vimentin (Fig. 4) and their presence was assessed repeatedly at different passages. During longterm cultivation, strong positivity for vimentin was continuously detected (Fig. 4a). In contrast, positivity for GFAP was strong in passage 1 and decreased quickly during the short-term cultivation (Fig. 4b), whereas nestin positivity increased markedly during the same period (Fig. 4c). After passage 6, the GM7 cell line showed low expression of GFAP and strong positivity for nestin and vimentin; these results were also confirmed by Western blot analysis (Fig. 5). During long-term cultivation, other intracellular and cell surface markers were also assessed (Fig. 4): the strong positivity for S100 protein (Fig. 4d) and NF160 (Fig. 4e) and low positivity for NSE (Fig. 4f) were found in the cytoplasm of GM7 cells; moreover, NSE was localized in the cell nuclei but not in nucleoli (Fig. 4f). Synaptophysin was not detected in GM7 cells. Finally, the GM7 cell line showed a strong positivity for cell surface antigen CD133 (Fig. $4 \mathrm{~h}$ and i), which is recognized to be a marker of neural stem cells.

Intracellular localization of steadily-expressed nestin. As we have previously reported (27), the most important feature of the GM7 cell line is the steady expression of nestin, especially its localization in the cell nucleus. Thus, we focused on the 


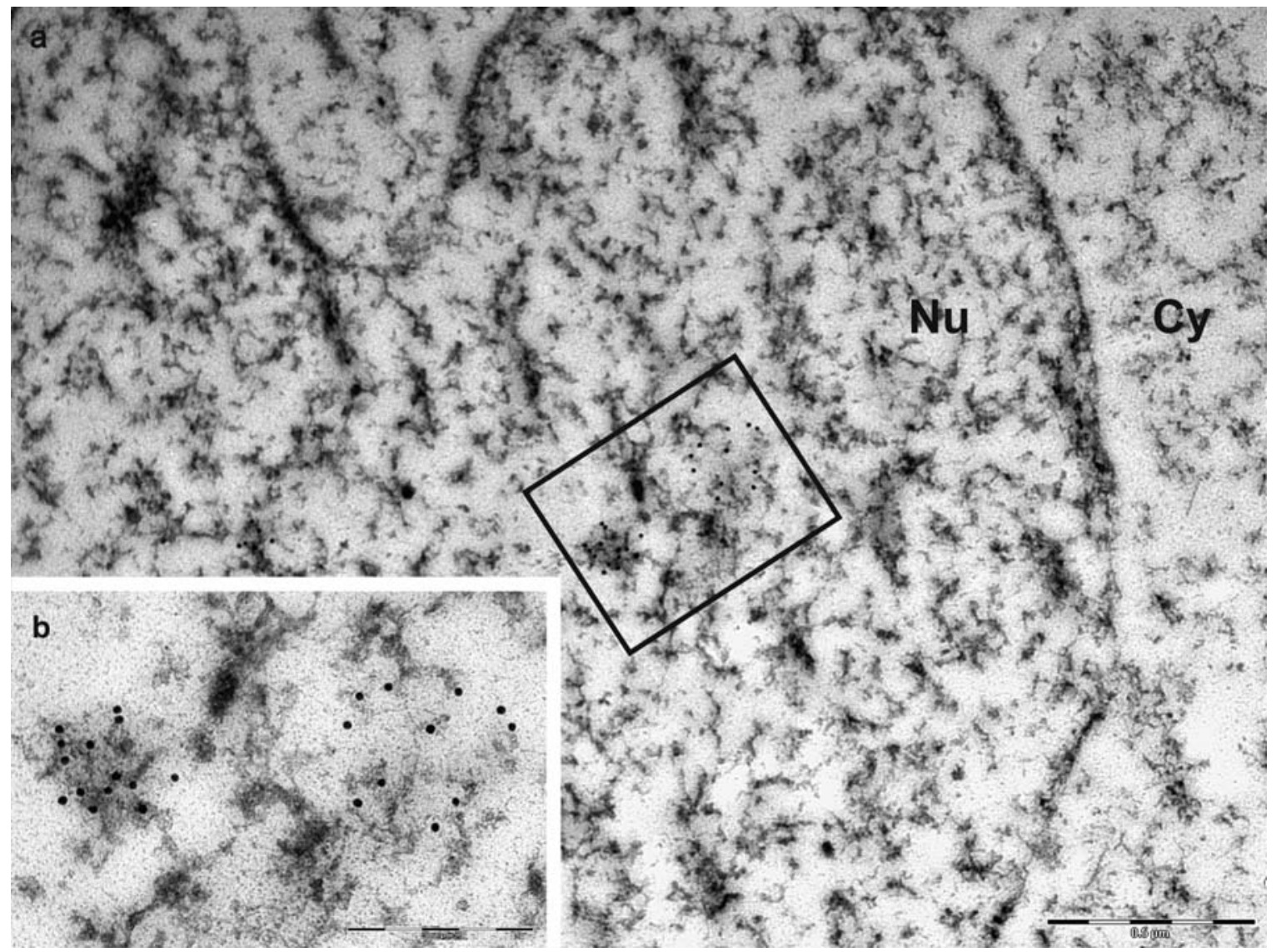

Figure 6. Detection of nestin in the cell nucleus. Nestin localization in cell nuclei was clearly confirmed by transmission electron microscopy using immunogold labeling (a and b). Cytoplasm (Cy) and nucleus (Nu) are indicated; bars, $0.5 \mu \mathrm{m}$ (a), $0.2 \mu \mathrm{m}$ (b).

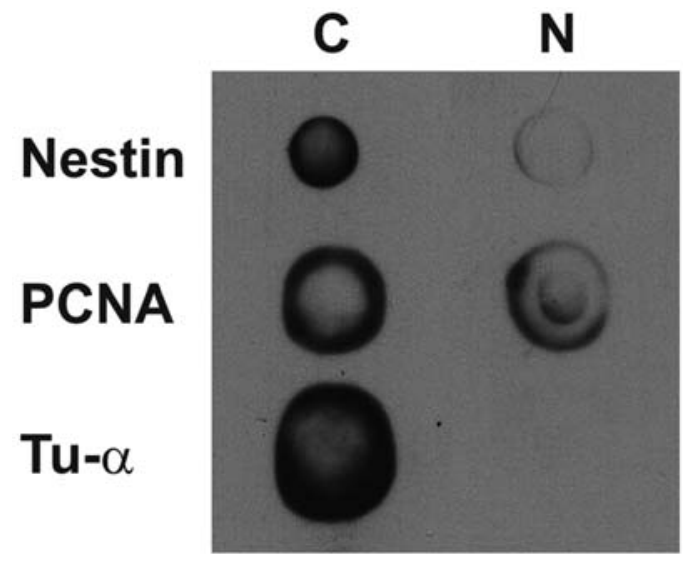

Figure 7. Dot-blot analysis of intracellular localization of nestin. GM7 cells were separated into cytoplasmic and nuclear fractions, which were immunodot-blotted for the presence of nestin. Additional immunoblots for PCNA (localized in nucleus and cytoplasm) and $\alpha$-tubulin (localized in cytoplasm only) were performed to confirm purity of the extracts.

detailed study of nestin localization in the GM7 cell line. The permanent occurrence of nestin in cell nuclei was repeatedly proven during long-term cultivation using immunocytochemical detection by confocal (Fig. $4 \mathrm{~g}$ ) and transmission electron microscopy (Fig. 6). Moreover, these results were confirmed by immuno-dot blot analysis of nuclear protein extracts (Fig. 7).

\section{Discussion}

In this study, we report the establishment and characterization of the GM7 permanent cell line. This cell line was derived from the tumor tissue of a patient surgically treated for relapse of glioblastoma multiforme 10 months after first surgery following radiotherapy. Although numerous human glioma cell lines have been reported, only a few of them were successfully established and propagated after radiotherapy or chemotherapy $(14,29,30)$. Onda and co-workers studied two cell lines derived from tumor samples taken from the same patient: one of them was a biopsy of primary tumor and the other of the tumor tissue after relapse. They found that the cell line derived from the relapsing tumor showed higher proliferation activity and more aggressive growth compared to the cell line derived from the primary tumor (30). Our results for growth parameters of the GM7 cell line also showed a very short PDT, albeit the cell line grew slower at early passages. A similar increase in cell proliferation activity during long-term cultivation of newly established high-grade astrocytoma cell lines has already been reported in the literature $(31,32)$.

Two cell types with different cell morphology are permanently observable in the culture: most of the cells exhibit spindle or glia-like morphology, although multinucleated giant 
cells are also present at a low frequency. The proportion of these cell types remains unchanged during long-term cultivation. Heterogeneity in glioblastoma histomorphology is well known and the presence of different cell types reflects that this phenomenon also occurs in in vitro conditions $(15,33,34)$. The morphology of glioblastoma cells in vitro may be stable $(14,35)$ or altered $(30)$. Similar differences in cell morphology were also shown in high-grade astrocytoma cell lines $(31,32)$.

Cytogenetic analysis showed that at early passages the GM7 cell line consists of near-triploid cells with a very complex karyotype. In addition, analysis of the DNA content by flow cytometry also confirmed the polyploidy of the GM7 cell line. These results are in accordance with many published findings that mainly demonstrated the polyploid karyotypes of permanent glioblastoma cell lines $(13,14,33)$. Heterogeneity in the karyotype of tumor cells may result in phenotypic heterogeneity, and some reports show that the changes in ploidy correlate with increased malignancy and growth rate $(36,37)$. Onda and co-workers also examined the DNA content in various glioma cultures at early passages. They concluded that cell cultures with changes in DNA ploidy have a higher potential to establish permanent glioma cell lines compared with cultures exhibiting a main diploid peak (30). Our results for several glioblastoma cell lines also confirmed this hypothesis: the near-triploid GM7 cell line was successfully maintained during long-term culture as reported herein, whereas a near-diploid GM10 cell line was only able to grow until 10-12 passages (27).

In addition to our findings for this cell line during shortterm culture (27), a detailed immunocytochemical analysis clearly proved the expression of main intracellular neuroglial protein markers in GM7 cells during long-term cultivation. Positivity for GFAP, vimentin and S-100 protein indicates that the GM7 cell line is derived from transformed glial cells. The presence of other neuroglial markers such as neurofilament, nestin and NSE, also confirmed a neuroectodermal origin of this cell line.

Very important finding on the GM7 cell line is its strong positivity for CD133 surface molecule, which is widely accepted to be a stem cell marker and its co-expression together with nestin in tumor tissue indicate the occurrence and localization of cancer stem cells (21-26). The CD133+/ nestin $^{+}$phenotype of GM7 cells suggest that this cell line represents a cell population with features of cancer stem cells.

Special attention was paid to the expression of three IF proteins - GFAP, vimentin and nestin - studied in this cell line continuously from early passages. The strong expression of vimentin was stable during long-term cultivation, in accordance with the confirmed glial origin of the GM7 cell line. More interesting results were obtained for the other two IF proteins - GFAP and nestin: although their expression was equally intermediate at the beginning of cell culture, a decrease in GFAP-positivity accompanied by increasing positivity for nestin was observed during short-term culture of this cell line (27). In addition, these changes in GFAP and nestin levels were repeatedly detected at different passages during longterm cultivation, as documented in this study.

Although the presence of GFAP is considered to be a characteristic marker of the astroglial lineage, published studies have shown a relatively small number of permanent glioma cell lines expressing GFAP continuously whereas decreasing GFAP expression during long-term cultivation was often reported $(38,39)$. Shenka and co-workers suggest that these differences in the immunocytochemical profile may be explained by variations in the concentration of microenvironment substances (39). For example, a decreased number of GFAP-positive cells together with an increased number of NSE-positive cells was reported for various glioma cell lines when the cells were exposed to lactic acid (40). Similarly, decreased expression of GFAP and increased nestin expression were reported in the U373MG glioblastoma cell line treated with TGF- $\alpha$; moreover, these experiments proved regulation of these changes at the transcriptional level (41). In contrast, up-regulation of GFAP expression was observed in glioblastoma cells after treatment with EGF, NGF, TGF-B, retinoic acid or cAMP (42).

Due to related mechanisms regulating levels of GFAP and nestin in U373MG glioblastoma cells (41), we also focused on the detailed analysis of nestin expression in the GM7 cell line. The class VI IF protein nestin is expressed in the proliferating neuroepithelium during CNS development in mammals, and is accepted to be a marker of neural stem cells in the developing and adult CNS (43-45). Nestin expression was also detected in many kinds of solid tumors, especially in tumors of neuroectodermal origin $(43,46-54)$. Higher levels of nestin in tumor cells were usually in correlation with increased aggressiveness of the respective tumor; nestin overexpression was also found in the infiltrating parts of highly metastatic glioblastomas and astrocytomas. Such findings suggest that nestin may play an important role in tumor progression (43,54-56).

This hypothesis was strongly supported by detection of nestin in the cell nuclei of some aggressive types of human solid tumors. The presence of nestin molecules in the cell nucleus was documented in glioblastoma and neuroblastoma cell lines $(27,57)$, as well as in tissue sections of some malignant angiosarcomas and GISTs (54). Although the role of nestin molecules in the cell nucleus still remains unclear, we hypothesize that this protein may participate either in chromatin organization or in the regulation of gene expression (27).

In any case, this permanent glioblastoma cell line steadily expressing nestin both in the cytoplasm and cell nucleus represents an extremely suitable model for further studies on the role of nestin in tumorigenesis. From this point of view, the GM7 cell line is unique due to the combination of $\mathrm{CD}_{13}{ }^{+} /$ nestin $^{+}$phenotype and steady nuclear localization of nestin. Since no established human tumor cell line has been described with regard to intracellular nestin localization, the wellcharacterized GM7 glioblastoma cell line may be a helpful model for cellular and molecular studies on this topic.

\section{Acknowledgements}

We thank Mrs. Johana Maresova and Mrs. Renata Kupska for their skillful technical assistance and Dipl. Ing. Ladislav Ilkovics (Department of Histology and Embryology, School of Medicine, Masaryk University, Brno) for his assistance in performing electron microscopy. This study was supported by grants: VZ MSM 0021622415, COST OC B19.001 and GACR 204/08/H054. 


\section{References}

1. Mao X and Hamoudi RA: Molecular and cytogenetic analysis of glioblastoma multiforme. Cancer Genet Cytogenet 122: 87-92, 2000.

2. Prados MD and Levin V: Biology and treatment of malignant glioma. Semin Oncol 27: 1-10, 2000.

3. Batchelor TT, Betensky RA, Esposito JM, et al: Age-dependent prognostic effects of genetic alterations in glioblastoma. Clin Cancer Res 10: 228-233, 2004.

4. Simmons ML, Lamborn KR, Takahashi M, et al: Analysis of complex relationships between age, p53, epidermal growth factor receptor, and survival in glioblastoma patients. Cancer Res 61: 1122-1128, 2001.

5. Stark AM, Witzel P, Strege RJ, Hugo HH and Mehdorn HM: p53, mdm2, EGFR, and msh2 expression in paired initial and recurrent glioblastoma multiforme. J Neurol Neurosurg Psychiatry 74: 779-783, 2003.

6. Necesalova E, Vranova V, Kuglik P, et al: Incidence of the main genetic markers in glioblastoma multiforme is independent of tumor topology. Neoplasma 54: 212-218, 2007.

7. Vranova V, Necesalova E, Kuglik P, et al: Screening of genomic imbalances in glioblastoma multiforme using highresolution comparative genomic hybridization. Oncol Rep 17: 457-464, 2007.

8. Amalfitano G, Chatel M, Paquis P and Michiels JF: Fluorescence in situ hybridization study of aneuploidy of chromosomes 7 , $10, \mathrm{X}$, and $\mathrm{Y}$ in primary and secondary glioblastomas. Cancer Genet Cytogenet 116: 6-9, 2000.

9. Morrison CD and Prayson RA: Immunohistochemistry in the diagnosis of neoplasms of the central nervous system. Semin Diagn Pathol 17: 204-215, 2000.

10. Perzelova A, Macikova, Tardy M, Mraz P, Steno J and Bizik I: Co-expression of GFAP, vimentin and cytokeratins in GL-15 glioblastoma cell line. Neoplasma 47: 362-366, 2000.

11. Miller CR and Perry A: Glioblastoma. Arch Pathol Lab Med 131: 397-406, 2007

12. Bacciocchi G, Gibelli N, Zibera C, et al: Establishment and characterization of two cell lines derived from human glioblastoma multiforme. Anticancer Res 12: 853-861, 1992.

13. Bakir A, Gezen F, Yildiz O, et al: Establishment and characterization of a human glioblastoma multiforme cell line. Cancer Genet Cytogenet 103: 46-51, 1998

14. Di Tomaso E, Pang JC, Lam HK, Tian XX, Suen KW, Hui AB and Hjelm NM: Establishment and characterization of a human cell line from paediatric cerebellar glioblastoma multiforme. Neuropathol Appl Neurobiol 26: 22-30, 2000.

15. Ishiwata I, Ishiwata $\mathrm{C}$, Ishiwata $\mathrm{E}$, et al: Establishment and characterization of human glioblastoma cell line (HUBT-n). Hum Cell 18: 59-65, 2005.

16. Badie B, Goh CS, Klaver J, Herweijer H and Boothman DA: Combined radiation and p53 gene therapy of malignant glioma cells. Cancer Gene Ther 6: 155-162, 1999.

17. Komata T, Kondo Y, Kanzawa T, et al: Caspase-8 gene therapy using the human telomerase reverse transcriptase promoter for malignant glioma cells. Hum Gene Ther 13: 1015-1025, 2002.

18. Chan JA, Krichevsky AM and Kosik KS: MicroRNA-21 is an antiapoptotic factor in human glioblastoma cells. Cancer Res 65: 6029-6033, 2005.

19. Vogel TW, Zhuang Z, Li J, et al: Proteins and protein pattern differences between glioma cell lines and glioblastoma multiforme. Clin Cancer Res 11: 3624-3632, 2005.

20. Uzzaman M, Keller G and Germano IM: Enhanced proapoptotic effects of tumor necrosis factor-related apoptosis-inducing ligand on temozolomide-resistant glioma cells. J Neurosurg 106: 646-651, 2007.

21. Pilkington GJ: Cancer stem cells in the mammalian central nervous system. Cell Prolif 38: 423-433, 2005.

22. Hemmati HD, Nakano I, Lazareff JA, Masterman-Smith M, Geschwind DH, Bronner-Fraser $M$ and Kornblum HI: Cancerous stem cells can arise from pediatric brain tumors. Proc Natl Acad Sci USA 100: 15178-15183, 2003.

23. Singh SK, Clarke ID, Terasaki M, Bonn VE, Hawkins C, Squire J and Dirks PB: Identification of a cancer stem cell in human brain tumors. Cancer Res 63: 5821-5828, 2003.

24. Singh SK, Hawkins C, Clarke ID, et al: Identification of human brain tumour initiating cells. Nature 432: 396-401, 2004.

25. Liu G, Yuan X, Zeng Z, et al: Analysis of gene expression and chemoresistance of $\mathrm{CD} 133^{+}$cancer stem cells in glioblastoma. Mol Cancer 5: 67, 2006.
26. Klein WM, Wu BP, Zhao S, Wu H, Klein-Szanto AJ and Tahan SR: Increased expression of stem cell markers in malignant melanoma. Mod Pathol 20: 102-107, 2007.

27. Veselska R, Kuglik P, Cejpek P, Svachova H, Neradil J, Loja T and Relichova $\mathrm{J}$ : Nestin expression in the cell lines derived from glioblastoma multiforme. BMC Cancer 6: 32, 2006.

28. Loja T, Kuglik P, Oltova A, Smuharova P, Zitterbart K, Bajciova V and Veselska R: The optimization of sample treatment for spectral karyotyping with applications for human tumour cells. Cytogenet Genome Res 116: 186-193, 2007.

29. Allalunis-Turner MJ, Barron GM, Day RS III, Dobler KD and Mirzayans R: Isolation of two cell lines from a human malignant glioma specimen differing in sensitivity to radiation and chemotherapeutic drugs. Radiat Res 134: 349-354, 1993.

30. Onda K, Nagai S, Tanaka R, Morii K, Yoshimura JI, Tsumanuma I and Kumanishi T: Establishment of two glioma cell lines from two surgical specimens obtained at different times from the same individual. J Neurooncol 41: 247-254, 1999.

31. Grippo MC, Penteado PF, Carelli EF, Cruz-Hofling MA and Verinaud L: Establishment and partial characterization of a continuous human malignant glioma cell line: NG97. Cell Mol Neurobiol 21: 421-428, 2001.

32. Machado CM, Schenka A, Vassallo J, Tamashiro WM, Goncalves EM, Genari SC and Verinaud L: Morphological characterization of a human glioma cell line. Cancer Cell Int 5: $13,2005$.

33. Perzelova A, Macikova I, Mraz P, Bizik I and Steno J: Characterization of two new permanent glioma cell lines 8MG-BA and 42-MG-BA. Neoplasma 45: 25-29, 1998.

34. Nuki Y, Uchinokura S, Miyata S, et al: Establishment and characterization of a new human glioblastoma cell line, NYGM. Hum Cell 17: 145-150, 2004.

35. Zhang L, Yamane T, Satoh E, et al: Establishment and partial characterization of five malignant glioma cell lines. Neuropathology 25: 136-143, 2005.

36. Garcia R, Bueno A, Castanon S, et al: Study of the DNA content by flow cytometry and proliferation in 281 brain tumors. Oncology 54: 112-117, 1997.

37. Gasinska A, Krzyszkowski T, Skolyszewski J, Biesaga B, Glinski B and Pyrich M: Flow cytometric analysis of DNA ploidy and proliferative potential in brain tumours. Folia Histochem Cytobiol 36: 133-138, 1998.

38. Quentmeier H, Osborn M, Reinhardt J, Zaborski M and Drexler HG: Immunocytochemical analysis of cell lines derived from solid tumors. J Histochem Cytochem 49: 1369-1378, 2001.

39. Schenka AA, Machado CM, Grippo MC, et al: Immunophenotypic and ultrastructural validation of a new human glioblastoma cell line. Cell Mol Neurobiol 25: 929-941, 2005.

40. Takeshita I, Sawa H, Nakamura T, Kuramitsu M, Kitamura K and Fukui M: Contrary effect of lactic acid on expression of neuron-specific enolase and glial fibrillary acidic protein in human glioma cells. Acta Neuropathol (Berl) 79: 506-512, 1990.

41. Zhou R and Skalli O: TGF- $\alpha$ differentially regulates GFAP, vimentin, and nestin gene expression in U-373 MG glioblastoma cells: correlation with cell shape and motility. Exp Cell Res 254: 269-278, 2000.

42. U HS, Espiritu OD, Kelley PY, Klauber MR and Hatton JD: The role of the epidermal growth factor receptor in human gliomas. II. The control of glial process extension and the expression of glial fibrillary acidic protein. J Neurosurg 82 : 847-857, 1995.

43. Dahlstrand J, Collins VP and Lendahl U: Expression of the class VI intermediate filament nestin in human central nervous system tumors. Cancer Res 52: 5334-5341, 1992.

44. Dahlstrand J, Lardelli M and Lendahl U: Nestin mRNA expression correlates with the central nervous system progenitor cell in many, but not all, regions of developing central nervous system. Brain Res Dev Brain Res 84: 109-129, 1995.

45. Reynolds BA and Weiss S: Generation of neurons and astrocytes from isolated cells of the adult mammalian central nervous system. Science 255: 1707-1710, 1992.

46. Florenes VA, Holm R, Myklebost O, Lendahl U and Fodstad O: Expression of the neuroectodermal intermediate filament nestin in human melanomas. Cancer Res 54: 354-356, 1994.

47. Kobayashi M, Sjoberg G, Soderhall S, Lendahl U, Sandstedt B and Sejersen T: Pediatric rhabdomyosarcomas express the intermediate filament nestin. Pediatr Res 43: 386-392, 1998. 
48. Tsujimura T, Makiishi-Shimobayashi C, Lundkvist J, et al: Expression of the intermediate filament nestin in gastrointestinal stromal tumors and interstitial cells of Cajal. Am J Pathol 158: 817-823, 2001

49. Almqvist PM, Mah R, Lendahl U, Jacobsson B and Hendson G: Immunohistochemical detection of nestin in pediatric brain tumors. J Histochem Cytochem 50: 147-158, 2002.

50. Sarlomo-Rikala M, Tsujimura T, Lendahl U and Miettinen M: Patterns of nestin and other intermediate filament expression distinguish between gastrointestinal stromal tumors, leiomyomas and schwannomas. APMIS 110: 499-507, 2002.

51. Ehrmann J, Kolar Z and Mokry J: Nestin as a diagnostic and prognostic marker: immunohistochemical analysis of its expression in different tumours. J Clin Pathol 58: 222-223, 2005.

52. Fujita S, Hideshima K and Ikeda T: Nestin expression in odontoblasts and odontogenic ectomesenchymal tissue of odontogenic tumours. J Clin Pathol 59: 240-245, 2006.
53. Schiffer D, Manazza A and Tamagno I: Nestin expression in neuroepithelial tumors. Neurosci Lett 400: 80-85, 2006.

54. Yang XH, Wu LQ, Yu XB, et al: Nestin expression in different tumors and its relevance to malignant grade. J Clin Pathol 61: 467-473, 2007.

55. Holland EC: Progenitor cells and glioma formation. Curr Opin Neurol 14: 683-688, 2001

56. Ignatova TN, Kukekov VG, Laywell ED, Suslov ON, Vrionis FD and Steindler DA: Human cortical glial tumors contain neural stem-like cells expressing astroglial and neuronal markers in vitro. Glia 39: 193-206, 2002.

57. Thomas SK, Messam CA, Spengler BA, Biedler JL and Ross RA Nestin is a potential mediator of malignancy in human neuroblastoma cells. J Biol Chem 279: 27994-27999, 2004 